\title{
Patterns of genetic structure and evidence of Egyptian Citrus rootstock based on informative SSR, LTR-IRAP and LTR-REMAP molecular markers
}

Mohamed Abd S. El zayat ${ }^{\dagger}$, Ahmed H. Hassan, Elsayed Nishawy ${ }^{\dagger}$, Mohammed Ali and Mohamed Hamdy Amar ${ }^{*}$

\begin{abstract}
Background: Releasing the draft genome of sweet orange provides useful information on genetic structure and molecular marker association with heritable breeding traits in citrus species and their structures. Last decades, microsatellite and retrotransposons are well known as a significant diverse component of the structural evolution. They represented the most potent elements for assessing sustainable utilization of the complicated classification in citrus breeding. Our study was performed to verify the structure analysis and the parentage genetic diversity among the Egyptian citrus rootstocks and the related species.

Results: Here, the performance of 26 SSR and 14 LTR-IRAP in addition to 20 LTR-REMAP markers have been used to conduct the discriminating power and the status of the genetic structure analysis among twenty specimens of citrus genotypes. As a result, the three markers approach exhibited a remarkable variation among the tested genotypes. Overall, the three markers have different discrimination power; the co-dominant SSR markers can differentiate within the group level only in addition to the species level of sour orange, while the dominant markers LTR-IRAP had the ability to discriminate among the group level in addition to species level and the origin of acids. Similarly, LTR-REMAP is suitable for classifying the group level and species level for mandarins as well the origin of Egyptian acids; probably due to it is integration of SSR and LTR-IRAP techniques. Structure and PCoA results of LTRREMAP marker in strong support for the group structure of citrus species have been divided into four sets: acids, grapefruit/pummelo, mandarin/orange, and sour orange.

Conclusion: Our findings of the genetic structure analysis support the monophyletic nature of the citrus species; are able to provide unambiguous identification and disposition of true species and related hybrids like lemon, lime, citron, sour orange, grapefruit, mandarin, sweet orange, pummelo, and fortunella; and resulted in their placement in individual or overlap groups. The outcomes of these results will offer helpful and potential information for breeding programs and conservation approaches as a key stage toward identifying the interspecific admixture and the inferred structure origins of Egyptian citrus rootstock and acid cultivars.
\end{abstract}

Keywords: Citrus, Microsatellite, Retrotransposons, Structure analysis, PCoA

\footnotetext{
* Correspondence: mohamed.amar@wbgcas.cn

${ }^{\dagger}$ Mohamed Abd S. El zayat and Elsayed Nishawy contributed equally to this

work.

Egyptian Deserts Gene Bank, Desert Research Center, Cairo, Egypt
}

\section{Springer Open}

(c) The Author(s). 2021 Open Access This article is licensed under a Creative Commons Attribution 4.0 International License, which permits use, sharing, adaptation, distribution and reproduction in any medium or format, as long as you give appropriate credit to the original author(s) and the source, provide a link to the Creative Commons licence, and indicate if changes were made. The images or other third party material in this article are included in the article's Creative Commons licence, unless indicated otherwise in a credit line to the material. If material is not included in the article's Creative Commons licence and your intended use is not permitted by statutory regulation or exceeds the permitted use, you will need to obtain permission directly from the copyright holder. To view a copy of this licence, visit http://creativecommons.org/licenses/by/4.0/. 


\section{Background}

The release of the several plant genomes platform in the last decade enriched the genetic structure, molecular marker-assisted breeding, and the basis of molecular biological research, where the genomics data in citrus have accumulated rapidly after the release of the sweet orange draft genome [1]. Presently, the first draft genome of citrus provides valuable information resources for understanding and development of several repeated sequences approaches such as microsatellites and retrotransposons regions.

Microsatellites became the marker of choice in plant genetics and breeding research in citrus species [2-6]. In the last decades, the publicly available of citrus EST and BAC-end sequences provides promising information to detect SSR motif for the development of a large number of effective SSR markers; besides, it allows the linkage of heritage traits connected to genomic divergence in citrus germplasm [7].

As it is well known, plants contain extended repetitive elements, many of which are mobile genetic elements (transposons) that are capable of changing their position within the genome. Among these transposable elements, the retrotransposons constitute the largest group and are further grouped into two main classes depending on the presence or absence of flanking long terminal direct repeats (LTR) [2]. These LTR are highly conserved and are exploited for primer design in the development of retrotransposons-based markers [3]. Several retrotransposon-based marker systems have been developed like, inter-retrotransposon amplified polymorphism (IRAP) and retrotransposonmicrosatellite amplified polymorphism (REMAP) [4].

The IRAP is a promising marker due to its ability to detect the insertion polymorphisms by amplifying the portion of DNA between two retrotransposons [8, 9]. However, the REMAP is similar to IRAP, but one of the two primers matches a microsatellite motif $[10,11]$. In LTR-REMAP, anchor nucleotides are used at the three ends of the simple sequence repeat primer to avoid slippage of the primer between the individual simple sequence repeat motifs [9]. An anchored primer also prevents the detection of variation in repeat numbers within the microsatellite [12]. Abundant in most genomes, microsatellites, or SSR motifs seem to associate with retrotransposons and caused high mutation rates due to polymerase slippage. Therefore, they may be more effectiveness loci for genetic diversity, structure analysis, phylogeny, and plant genotyping within a species or sub-species $[13,14]$.

Citrus classification is complicated and confusing by many features, such as a long history of cultivation, bud mutation, nuclear embryonic, and a broad crosscompatibility between species and invasive species [15].
The most widely known taxonomic systems for citrus are Swingle [16] and Tanaka [17], who documented 16 and 162 species. Sweet orange, mandarin, pummelo, grapefruit, lemon, lime, and various hybrids are among the most commonly grown and economically important fruit tree crops in the genus citrus [18]. Hence, the development of citrus cultivar through conventional methods is quite problematic, ineffective, expensive, and time-consuming due to its prolonging juvenility, unusual sexual behavior, and complicated genetic background [19]. At present, the number of species to be recognized in citrus and the relationships among genotypes is the major problems in citrus classification [20].

Additionally, root stock has a powerful impact on yield, fruit quality, tree circumference and shape, beside that can also offer tolerance of biotic and abiotic stresses. In Egypt, several valid species or natural hybrids have served as highly effective root stocks involving sour orange, volkamer lemon, Egyptian lime, rough, and eureka lemon. These made citrus rootstock breeding a vital research activity globally. Therefore, the performance of the new species in Egypt should be considered before cultivating to preserve the citrus genetic resources against the invasive citrus species.

Conversely, genetic structure analysis and molecular evolution represent the most powerful tools for evaluating genomes and enabling the association of heritable traits with underlying genomic variation [21]. However, the enhanced performance of DNA markers and their transferability to present a broad presence of varieties also helped in revealing the confused genealogy of native citrus varieties and its origins [22]. Unfortunately, retrotransposons and microsatellites-based markers are still less explored in citrus research comparing to other plant species like Oryza, Triticum, and Brassica [23].

The present study, based on an extensive sampling from China and Egypt, measures structure analysis and the genetic diversity of Egyptian rootstocks and domesticated citrus species with its related. Through this research, the performance of the SSR, LTR-IRAP, and LTR-REMAP markers has been made to conduct the discriminating power and the status of genetic structure and phylogeny of the individual marker in the genus citrus and related species. This data will allow calculation of genetic diversity and the genetic structure within various Egyptian and Chinese citrus species, which has not been previously reported.

\section{Methods}

\section{Plant materials and genomic DNA isolation (gDNA)}

Twenty genotypes belong to the genus citrus and its relative species involved the following major groups of citrus as listed in Table 1. The samples were collected from the National Research Center, Egypt, and for the 
Table 1 The accession list of 20 citrus genotypes and its relatives used with SSR, LTR-IRAP and LTR-REMAP markers

\begin{tabular}{|c|c|c|c|c|}
\hline Sample No. & Genotype name & Scientific name & Type of fruit & Group name \\
\hline 1 & Fingered Citron & Citrus medica var sarcodactylis & & Citron \\
\hline 2 & Eureka Lemon & Citrus limon (L.) Burm. f. & Acids & Lemon \\
\hline 3 & Egyptian Eureka lemon & Citrus limon & & Lemon \\
\hline 4 & Rough lemon & Citrus limon (L.) Burm. f. & & Lemon \\
\hline 5 & Volkamer lemon & Citrus volkameriana & & Lemon \\
\hline 6 & Egyptian lime & Citrus aurantifolia (Christm.) Swingle & & Sour lime \\
\hline 7 & HB pummelo & Citrus maxima & Grapefruits and pummelos & Pummelo \\
\hline 8 & Shatian pummelo & Citrus maxima & & Pummelo \\
\hline 9 & Guan Xi Miyon pummelo & Citrus maxima & & Pummelo \\
\hline 10 & Red Marsh grapefruit & Citrus paradisi Macfad & & Grapefruit \\
\hline 11 & Ponkan & Citrus reticulata Blanco & Mandarins & Mandarin \\
\hline 12 & Guoqing & Citrus reticulata Blanco & & Mandarin \\
\hline 13 & Murcott & Citrus reticulata Blanco & & Mandarin \\
\hline 14 & Jincheng & Citrus sinensis Osbeck & Oranges & Sweet orange \\
\hline 15 & Valencia & Citrus sinensis Osbeck & & Sweet orange \\
\hline 16 & Anliu & Citrus sinensis Osbeck & & Sweet orange \\
\hline 17 & Cara Cara & Citrus sinensis Osbeck & & Navel orange \\
\hline 18 & Daidai & Citrus aurantium L. & & Sour orange \\
\hline 19 & Bitter orange & Citrus aurantium L. & & Sour orange \\
\hline 20 & Meiwa kumquat & Fortunella crassifolia Swingle & Kumquat & Kumquat \\
\hline
\end{tabular}

National Center of citrus Breeding (NCCB), Huazhong Agricultural University (HZAU), Wuhan, China. Genomic DNA of citrus species was extracted from the fresh leaves following the procedure as previously described elsewhere [24]. The quality and concentration of the DNA samples were checked using UV-1601 spectrophotometer (Shimadzu, Japan) and a sub-aliquot of the DNA was subsequently diluted to $50 \mathrm{ng} / \mu \mathrm{l}$. Both the stock and diluted portions were stored at $-20^{\circ} \mathrm{C}$.

\section{SSR analysis}

Twenty-six successful SSR primers were designed from the flanking sequences, using SSRLocatorI V1.1 software [25] according to the sweet orange draft genome and the publicly available of EST and BAC-end sequences in the citrus database (Table 2). PCR amplification reaction was prepared according to the previously described by Amar et al. [26] with minor modifications. PCR mix were performed as follows: in $20 \mu \mathrm{l}$ of reaction mixture containing $2 \mu \mathrm{l} \mathrm{10 \times}$ PCR buffer, $2 \mathrm{mmol} \mathrm{MgCl}_{2}, 200$ mmol dNTP, 4 pmol of each primer (forward and reverse), $50 \mathrm{ng}$ template DNA and $1 \mathrm{U}$ Taq DNA polymerase (Ferments). The amplification reaction procedure was as follows: after denaturation at $94{ }^{\circ} \mathrm{C}$ for $4 \mathrm{~min}$, the reaction mixture was subjected to amplification for 10 cycles consisting of $30 \mathrm{~s}$ at $94{ }^{\circ} \mathrm{C}, 30 \mathrm{~s}$ at $66^{\circ} \mathrm{C}$, and $45 \mathrm{~s}$ at $72{ }^{\circ} \mathrm{C}$, followed by 30 cycles consisting of $30 \mathrm{~s}$ at $94^{\circ} \mathrm{C}$,
$30 \mathrm{~s}$ at $55^{\circ} \mathrm{C}$, and $45 \mathrm{~s}$ at $72^{\circ} \mathrm{C}$ with a final extension of $72{ }^{\circ} \mathrm{C}$ for $10 \mathrm{~min}$. The amplification products were separated by $6 \%$ poly acrylamide gel electrophoresis (PAGE) and visualized by a simplified silver staining method previously described by $\mathrm{Xu}$ et al. [27].

\section{LTR-IRAP analysis}

Fourteen novel LTR-IRAP primers, including Ty1/copialike and Ty3/gypsy-like elements, were chosen for this study (Table 2). Primers were designed against the element's 5'end in the long terminal repeat (LTR) of each retrotransposon. The LTR-IRAP protocol was developed by adaptation of an original method of Kalendar et al. [10]. The amplification programmed consisted of predenaturation at $94{ }^{\circ} \mathrm{C}$ for $2 \mathrm{~min} ; 35$ cycles at $94{ }^{\circ} \mathrm{C}$ for 30 $\mathrm{s}, 60^{\circ} \mathrm{C} 30 \mathrm{~s}$, ramp $+0.53^{\circ} \mathrm{C} / \mathrm{s}, 72^{\circ} \mathrm{C}$ for $90 \mathrm{~s}$, and a final incubation at $72{ }^{\circ} \mathrm{C}$ for $10 \mathrm{~min}$. The PCR products were subjected to electrophoresis on a $2 \% \mathrm{NuSieve}^{\oplus}$ 3:1 agarose gel (Lonza Rockland, Inc.) in 1X TBE buffer stained with ethidium bromide and photographed in BIORAD automated Gel Documentation System (Italy).

\section{LTR-REMP analysis}

Ten primers synthesized from $T y$-1/copia and $T y 3$ gypsy-like sequences were combined with ten citrus SSR primers performing twenty nine LTR-SSR primer combinations (Table 2). The LTR-REMAP analysis was 
Table 2 List of SSR, LTR-IRAP, and LTR-REMAP primers sequence and its optimum annealing temperature

\begin{tabular}{|c|c|}
\hline \multicolumn{2}{|l|}{ A: SSR } \\
\hline Primer name & Forward \\
\hline SA1 & TGTATCCCTGCCGTTTCTTC \\
\hline SA2 & ACTTGGGGCTTTCTCACGTT \\
\hline SA3 & TCTCCGAACTCTCGCACTAAA \\
\hline SA4 & CAGTCGATTGTTTGCTGTGG \\
\hline SA5 & CCACCACTCAATTTTGCTGA \\
\hline SA6 & TCTCCGAACTCTCGCACTAAA \\
\hline SA7 & GAGAGAGGTGGCAATTGAGC \\
\hline SA8 & TCACAAATTTATGCCTTGCG \\
\hline SA9 & TCGAGAAAATTAAGTCTITTCTTCC \\
\hline SA10 & CCCAGGTTAGCAACTTCGTT \\
\hline SA11 & AGCCTTGGCTGAGCTGTAAA \\
\hline SA12 & CCGCCAGATTTTTCATTTTC \\
\hline SA13 & AAGAGCACTTGCCGAGGATA \\
\hline SA14 & CCAAGTTTTGCTTCCCTTGA \\
\hline SA15 & TCGAAGAGAGGGAGGAGTCA \\
\hline SA16 & CGGATGGAAGAAAACCTGAA \\
\hline SA17 & GCAGCCCTCAACATGATACA \\
\hline SA18 & TCTCСTCTCCTCTTGTTCTTCTTC \\
\hline SA19 & CGCTGAGAACTGAGAAGGAAA \\
\hline SA20 & AGTCTCTGGCCTTGCAGGTA \\
\hline SA21 & ATGGCTGCTCTCAAATGCTT \\
\hline SA22 & AGGATGCCATGTTGGTTCTC \\
\hline SA23 & GTGCAGCGCAACAACATAAC \\
\hline SA24 & GTCCGTTCTCCTCGCTCTTC \\
\hline SA25 & CGCATACATCATCATCGTCA \\
\hline SA26 & TGTATCCCTGCCGTTCTTC \\
\hline
\end{tabular}

\section{B: LTR-IRAP}

\section{Primer name}

LTR 1

LTR 2

LTR 3

LTR 4

LTR 5

LTR 6

$\operatorname{LTR} 7$

LTR 8

LTR 9

LTR 10

LTR 11

LTR 12

LTR 13

LTR 14

\section{Forward}

TGCCACGATCAGCAAGAATCA

AGTAACTGTAAGCTGACGTGGCT

CCGTITTGCCGTCTGATCTCT

TGTGGTGCAGTGAACCATTCA

GCTCTCTGGCTGTTATCGGTT

TGCGAATCCACATGGTGATCACA

TCGTCAATCCGCATGGCTTCCA

GATACCAGGCTCTTACGGGACAC

GACTTCGCCCAAACTTTGTGA

TCGCCGTTGTTCGTTGAGTGTCT

CAGCAACTGCACTGTTCCAGA

TGCGAATCCACATGGTGATCACA

CTCCTAATGGTTCCTAATACCAGACAA

GCAAACCAAGATTGGTGAGGGCA

\begin{tabular}{|c|c|}
\hline Reverse & $\mathrm{T}$ \\
\hline GAAACTTCCCACTTCGCTCA & 57 \\
\hline TTTGCCAGATATTGCTGCTG & 57 \\
\hline GGGGGATGTTGGAGATTITI & 58 \\
\hline TTCGGAAATTITTCTGTGGA & 57 \\
\hline GCATTCACACGATCCACATC & 55 \\
\hline GGGGGATGTTGGAGATTITI & 58 \\
\hline TTGCCTCACAACAAACAAAGA & 59 \\
\hline TCGATAGTGCACCACGACAT & 5 \\
\hline ATTCTTCGGTTCTTGGGCTT & 55 \\
\hline CAAAGTCAATTGGAATCTCCTTG & 5 \\
\hline GGGTGCCATTTAAAAACCCT & 5 \\
\hline GAATCCGCCACCAATTTAAC & 5 \\
\hline GAATCCCATTTGATCCGAGA & 57 \\
\hline AGCTCTGGTGGATTTCCTGA & 55 \\
\hline AGAACCACCCCCTTCTTTGT & 59 \\
\hline AGTCGAATTACGGGTTGCAG & 55 \\
\hline GCCGTCAACTTTCTTGCTTC & 57 \\
\hline TTGATGGTCTTGGAAGGGTC & 60 \\
\hline TGCAATTCGATGTTGTTCTTG & 58 \\
\hline GGATCAATGTCCCCAATCAC & 59 \\
\hline CTITCCTAAACCAGCTGCC & 5 \\
\hline CCATTGCTAGAAACTCCCCA & 57 \\
\hline GGCCAATAGCTTCCATTCAA & 57 \\
\hline TGTAGGTAGGCAACGGAAGG & 6 \\
\hline GCCTGGATACGTGAACCACT & כ5 \\
\hline GAAACTTCCCACTTCGCTCA & \\
\hline
\end{tabular}

\section{Reverse}

TCTCTTGACAATTCACGTGGCT

GGTGTTGTAGAATCTTCCAGACT 53

AATCCACCTCCTCGTGGGAT 58

TCGGCTGGAAACCCGAGCTTGC 59

AGGTTGGCCGAACCACGTAA 54

GGATCGTGATCTAGGAGCCTA 56

GACGTAGGCTAAAAGCCGACCA 57

CAACCGGCGTGCTCTGACTTGT 53

GTAGGCGGGGATTGCCGAACCA

CGAACCACGTAAAAATCCGCGTG 56

TCACTGTGGAGACGATCTTGA 55

TAGGAGCCTAAATCACTTCA 53

ACCTCTCGAATTGTAGGTCAGG 56

GCAACCCGTITCGTCCAGA 57 
Table 2 List of SSR, LTR-IRAP, and LTR-REMAP primers sequence and its optimum annealing temperature (Continued)

\begin{tabular}{ll}
\hline C: LTR-REMAP & \\
Primer name & Primer combination \\
SA1-REMAP & F 1 REMAP/R AM-SSR10 \\
SA2-REMAP & F 2 REMAP/R AM-SSR12 \\
SA3-REMAP & F 3 REMAP/R AM-SSR17 \\
SA4-REMAP & F 4 REMAP/R AM-SSR25 \\
SA5-REMAP & F 5 REMAP/R AM-SSR22 \\
SA6-REMAP & F 6 REMAP/R AM-SSR24 \\
SA7-REMAP & F 7 REMAP/R AM-SSR23 \\
SA8-REMAP & F 8 REMAP/R AM-SSR2 \\
SA9-REMAP & F 9 REMAP/R AM-SSR11 \\
SA10-REMAP & F 10 REMAP/R AM-SSR14 \\
SA11-REMAP & F 1 REMAP/R AM-SSR6 \\
SA12-REMAP & F 2 REMAP/R AM-SSR9 \\
SA13-REMAP & F 3 REMAP/R AM-SSR11 \\
SA14-REMAP & F 4 REMAP/R AM-SSR8 \\
SA15-REMAP & F 5 REMAP/R AM-SSR6 \\
SA16-REMAP & F 10 REMAP/R AM-SSR12 \\
SA17-REMAP & F 11 REMAP/R AM-SSR5 \\
SA18-REMAP & F 12 REMAP/R AM-SSR12 \\
SA19-REMAP & F 13 REMAP/R AM-SSR16 \\
SA20-REMAP & F 14 REMAP/R AM-SSR14 \\
\hline &
\end{tabular}

executed following Kalendar et al. [10]. The thermal cycling was programmed as initial denaturation cycle at $94^{\circ} \mathrm{C}$ for $4 \mathrm{~min}$, followed by 35 cycles at $94{ }^{\circ} \mathrm{C}$ for $45 \mathrm{~s}$, $55^{\circ} \mathrm{C}$ for $40 \mathrm{~s}$, and $72{ }^{\circ} \mathrm{C}$ for $1 \mathrm{~min}$ for denaturation, annealing and extension, respectively. A final extension step was performed at $72{ }^{\circ} \mathrm{C}$ for $10 \mathrm{~min}$. Then, amplification products were separated and visualized following the same procedure described for LTR-IRAP.

\section{Data scoring and polymorphism analysis}

Only reproducible amplicons of each replication will be scored. Consensus profiles were verified based on the presence (1) or absence (0) of amplicons and assembled onto a data matrix. Comparisons of the discriminating capacity, level of polymorphism, and informativeness of each marker system of SSR, LTR-IRAP, and LTRREMAP were assessed using GenAlEx software [28]. To compare the efficiency of the three markers in citrus species, we estimated the following parameters: $(N)$ number of species per group, $(\mathrm{Na})$ number of different alleles, $(\mathrm{Na} / \mathrm{b})$ number of alleles or bands, $(\% P)$ the percentage of polymorphism, (Ne) number of effective alleles, (I) Shannon's index, and (uHe) unbiased expected heterozygosity (Table 3 ).

\section{Species diversity and clustering}

Principal coordinate analysis (PCoA) will be carried out to display the multidimensional genetic relationship and its partition among varieties [29]. To gain further perspectives on the genetic structure among the citrus germplasm, the Bayesian clustering method to infer the pattern of genetic structure was employed using STRUCTURE 2.2.3 [30, 31]. To estimate the best number of clusters, three independent simulations were achieved per number of sub-groups $\mathrm{K}$ (30 runs of $\mathrm{K}=$ $1-10)$. The ideal $K$ number is created on the highest average of the estimated ln probability score that shows the lowest variance for each run. The bar plot of the Structure output was colored according to the K number of sub-groups of the maximum likelihood log with the lowest variation.

\section{Results}

Level of polymorphism and discriminating power

In this study, we used a total of 20 genotypes of citrus and its related species, to investigate either SSR, LTRIRAP, or LTR-REMAP markers were polymorphic sufficient to be suitable for genotype discrimination and breeding programs of citrus. These species were divided into five groups according to the morphological 
Table 3 Levels of effective alleles, Shannon's information index, unbiased expected heterozygosity value, No. of private alleles, and No. of LComm alleles ingenerated by SSR, LTR-IRAP, and LTR-REMAP assays for 20 citrus genotypes

\begin{tabular}{|c|c|c|c|c|c|c|c|c|c|c|c|c|c|c|}
\hline Marker system & Group & $N$ & $\mathrm{Na} / \mathrm{b}$ & $\% P$ & $\mathrm{Na}$ & SE & $\mathrm{Ne}$ & SE & $I$ & SE & uHe & SE & $\begin{array}{l}\text { N. private } \\
\text { alleles }\end{array}$ & $\begin{array}{l}\text { N. LComm alleles } \\
(\leq \mathbf{5 0 \% )}\end{array}$ \\
\hline \multirow[t]{5}{*}{ SSR } & Kumquat & 1 & 41 & $70.83 \%$ & 1.71 & 0.09 & 1.71 & 0.09 & 0.49 & 0.07 & 0.71 & 0.09 & 0.208 & 0.292 \\
\hline & Acids & 6 & 75 & $95.83 \%$ & 3.13 & 0.26 & 2.27 & 0.17 & 0.87 & 0.08 & 0.54 & 0.04 & 0.667 & 0.542 \\
\hline & Grapefruits and pummelos & 4 & 58 & $79.17 \%$ & 2.42 & 0.22 & 1.93 & 0.18 & 0.64 & 0.09 & 0.43 & 0.06 & 0.208 & 0.333 \\
\hline & Mandarins & 3 & 54 & $91.67 \%$ & 2.25 & 0.16 & 1.88 & 0.15 & 0.64 & 0.07 & 0.49 & 0.05 & 0.167 & 0.250 \\
\hline & Oranges & 6 & 64 & $95.83 \%$ & 2.67 & 0.17 & 2.21 & 0.13 & 0.82 & 0.06 & 0.56 & 0.03 & 0.083 & 0.333 \\
\hline \multirow[t]{5}{*}{ LTR-IRAP } & Kumquat & 1 & 61 & $0.00 \%$ & 0.40 & 0.04 & 1.00 & 0.00 & 0.00 & 0.00 & 0.00 & 0.00 & 10 & 8 \\
\hline & Acids & 6 & 104 & $60.53 \%$ & 1.29 & 0.07 & 1.31 & 0.03 & 0.29 & 0.02 & 0.21 & 0.02 & 19 & 21 \\
\hline & Grapefruits and pummelos & 4 & 67 & $22.37 \%$ & 0.66 & 0.07 & 1.16 & 0.03 & 0.13 & 0.02 & 0.10 & 0.02 & 5 & 8 \\
\hline & Mandarins & 3 & 84 & $36.18 \%$ & 0.91 & 0.07 & 1.23 & 0.03 & 0.20 & 0.02 & 0.16 & 0.02 & 6 & 15 \\
\hline & Oranges & 6 & 89 & $45.39 \%$ & 1.04 & 0.08 & 1.30 & 0.03 & 0.25 & 0.02 & 0.18 & 0.02 & 5 & 12 \\
\hline \multirow[t]{5}{*}{ LTR-REMAP } & Kumquat & 1 & 100 & $0.00 \%$ & 0.33 & 0.03 & 1.00 & 0.00 & 0.00 & 0.00 & 0.00 & 0.00 & 15 & 24 \\
\hline & Acids & 6 & 182 & $57.00 \%$ & 1.18 & 0.06 & 1.27 & 0.02 & 0.27 & 0.01 & 0.19 & 0.01 & 24 & 40 \\
\hline & Grapefruits and pummelos & 4 & 152 & $29.67 \%$ & 0.80 & 0.05 & 1.20 & 0.02 & 0.17 & 0.02 & 0.13 & 0.01 & 15 & 25 \\
\hline & Mandarins & 3 & 129 & $25.67 \%$ & 0.69 & 0.05 & 1.17 & 0.02 & 0.15 & 0.01 & 0.12 & 0.01 & 10 & 14 \\
\hline & Oranges & 6 & 197 & $59.00 \%$ & 1.25 & 0.05 & 1.32 & 0.02 & 0.29 & 0.02 & 0.21 & 0.01 & 15 & 51 \\
\hline
\end{tabular}

$N$ No. of species per group, $\mathrm{Na} / \mathrm{b}$ No. of alleles or bands, \% Percentage of polymorphic loci, $\mathrm{Na}$ No. of different alleles, Ne No. of effective alleles, I Shannon's Information Index

description and fruit characterization as following, acids (six species), grapefruits and pummelos (four species), mandarins (three species), oranges (six species), and a unique kumquat species (Table 1). All marker systems observed turned out to be beneficial tools for detecting polymorphism and assessing genetic diversity in citrus germplasm, while the degree of resolution differed on the applied technique. We primarily tested 70 SSR, 35 LTR-IRAP, and 50 REPAP primers between the five citrus germplasm groups. Among all, 26 SSR, 14 LTRIRAP, and 20 LTR-REMAP primers provided high polymorphism levels as presented in Table 2 and Fig. 1a-c. Within the three markers system, SSR followed by LTRIRAP and LTR-REMAP presented diverse polymorphism levels as shown in (Table 3 and Fig. 2). However, in SSR markers, the acid species had superior $\mathrm{Na} / \mathrm{b}, \% \mathrm{P}, \mathrm{Na}, \mathrm{Ne}$, and $\mathrm{I}$, with mean of $75,95.83 \%$, and $3.13 \pm 0.26$, and $2.27 \pm 0.17$ and $0.87 \pm 0.08$, respectively. Meanwhile, the lowest $\mathrm{Na} / \mathrm{b}, \% P, \mathrm{Na}, \mathrm{Ne}$, and $I$ appeared only in kumquat species with $41,70.83,1.71 \pm 0.09$, and $1.71 \pm 0.09$, $0.49 \pm 0.07$, respectively. In contrast, Kumquat species exhibited the greatest value of $\mathrm{uHe}$ with mean of $1.71 \pm$ 0.09. In LTR-IRAP markers, acids species had the higher values in all parameters with mean of 104 for $\mathrm{Na} / \mathrm{b}$, $60.53 \%$ for $\% P, 1.29 \pm 0.07$ for $\mathrm{Na}, 1.31 \pm 0.03$ for $\mathrm{Ne}$, $0.29 \pm 0.02$ for $I$, and $0.21 \pm 0.02$ for uHe, while the grapefruits and pummelos presented the lowest value of $\mathrm{Na} / \mathrm{b}, \% P, \mathrm{Na}, \mathrm{Ne}, I$, and $\mathrm{uHe}$ with mean of $67,22.37 \%$, $0.66 \pm 0.07,1.16 \pm 0.03,0.13 \pm 0.02$, and $0.10 \pm 0.02$, respectively. On behalf to the LTR-REMAP markers, oranges showed the high proportions of $\mathrm{Na} / \mathrm{b}, \% P, \mathrm{Na}$, $\mathrm{Ne}, I$, and $\mathrm{uHe}$ with mean of $197,59 \%, 1.25 \pm 0.05,1.32$ $\pm 0.02,0.29 \pm 0.02$, and $0.21 \pm 0.01$, respectively. In contrast, mandarins revealed the minority of $\mathrm{Na} / \mathrm{b}, \% P, \mathrm{Na}$, $\mathrm{Ne}, I$, and uHe with mean of $129,25.67 \%, 0.69 \pm 0.05$, $1.17 \pm 0.02,0.15 \pm 0.01$, and $0.12 \pm 0.01$, respectively.

Concerning the behavior of the private alleles (or bands), it correlates positively with the LComm alleles $(\leq 50 \%)$ across the three markers system (Table 3$)$. Within the species group, acids are the greatest private alleles (in SSR) and banding patterns (in LTR-IRAP and LTRREMAP), being $0.667,19$, and 24 , respectively. In contrast, oranges exhibited the lowest private alleles in SSR with a mean of 0.083 , while oranges, grapefruits and pummelos, and mandarins showed slightly lower banding patterns in LTR-REMAP being 15, 15, and 10, respectively. Furthermore, oranges, grapefruits and pummelos, and mandarins recorded the lowermost values of banding patterns in LTR-IRAP being 5, 5, and 6, respectively. Table 4 shows the results for the coefficients correlation $(r)$ among the three markers with similarity matrices are presented. Values of $r$ were significant correlations were observed when comparing the SSR and LTR-IRAP (0.97) markers and between LTR-IRAP and LTR-REMAP (0.95).

\section{Species diversity and genetic structure}

To further determine the genetic relationships among the citrus species and the resolution of the individual markers, a graphic demonstration of the principal coordinate analysis (PCoA) was constructed to express the 


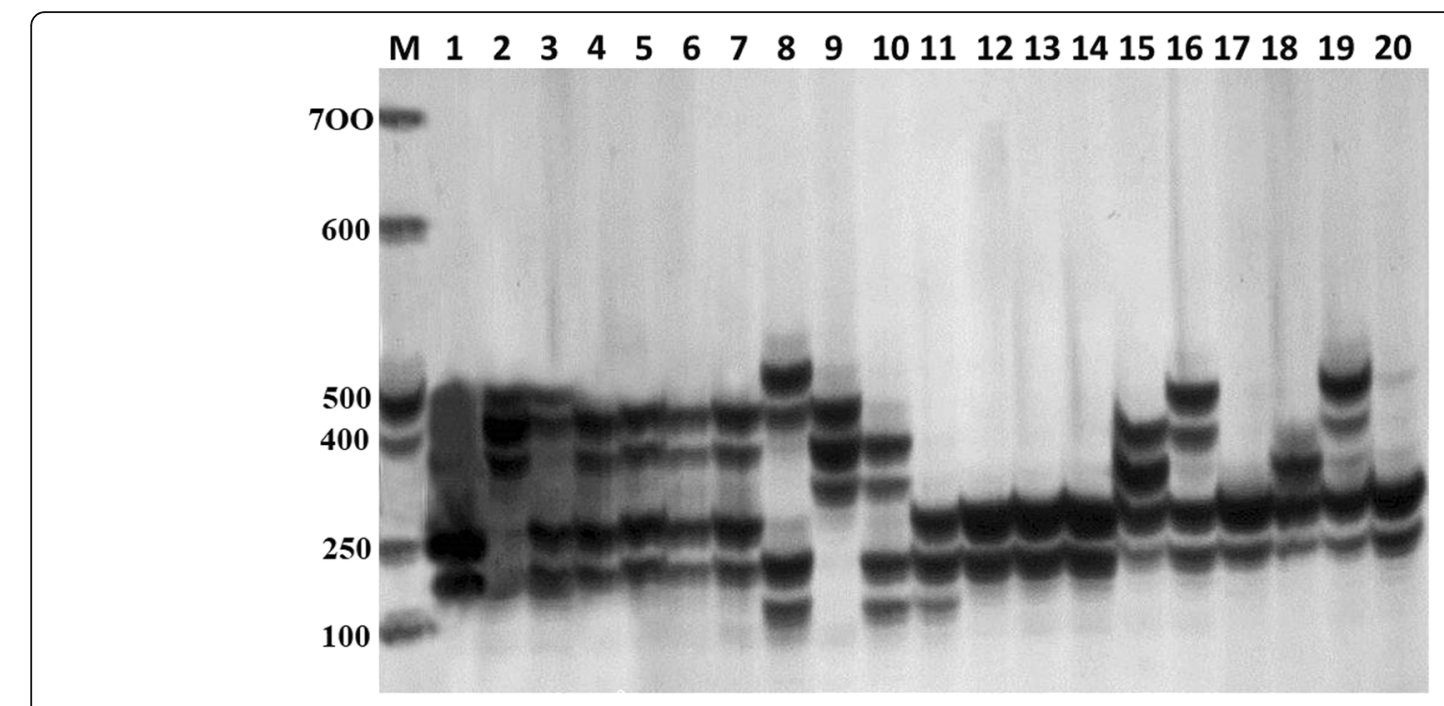

(a) SSR: Primer MA SSR 20

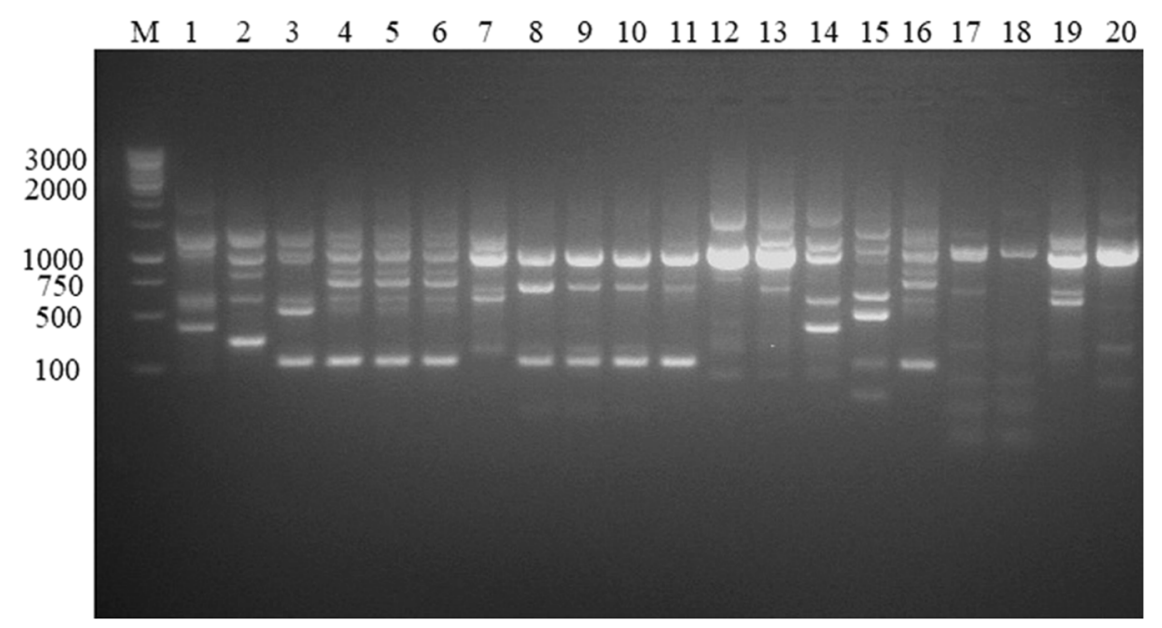

(b) LTR-IRAP: Primer MA LTR-13

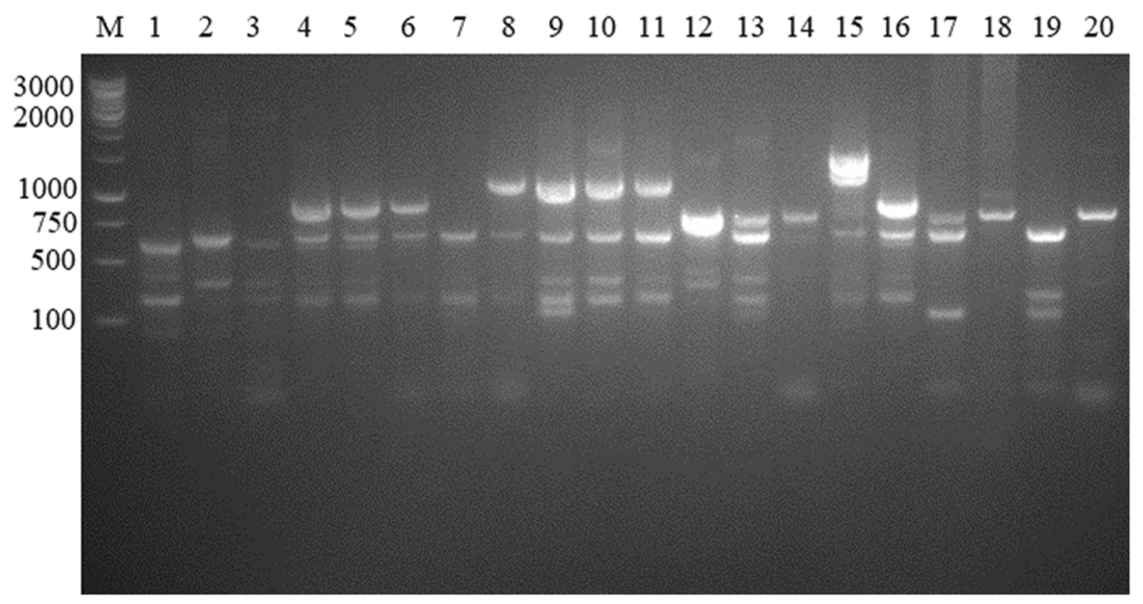

(c) LTR-REMAP: Primer MA SSR 10/LTR-8

Fig. 1 a SSR, b LTR-IRAP, and c LTR-REMAP profiles of 20 citrus genotypes 


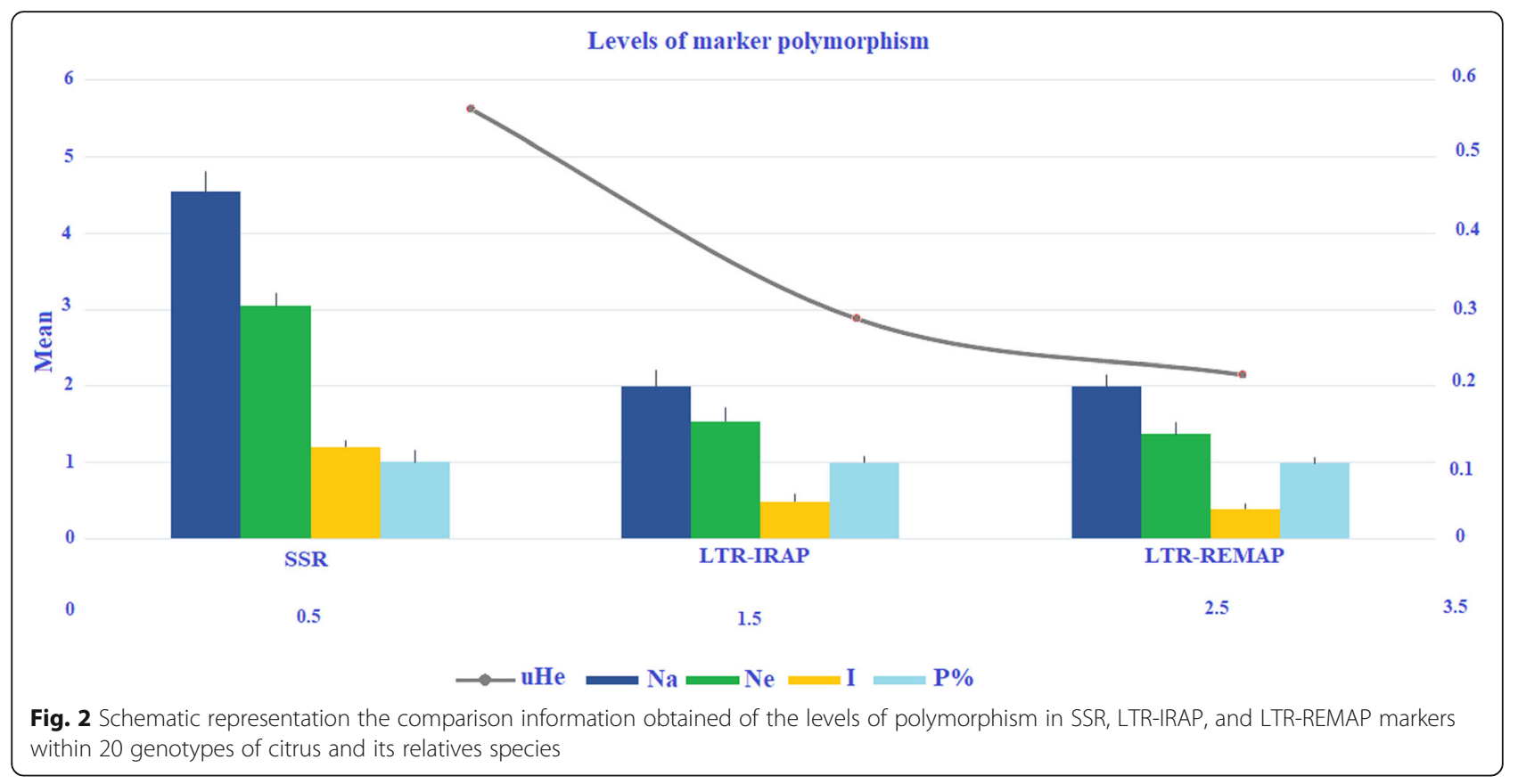

results based on data obtained from the SSR, LTR-IRAP, and LTR-REMAP markers. The two-dimensional PCoA plot separated the studied species within the standard four quadrates. The PCoA plot for SSR data revealed 40.11\% and $71.53 \%$ of the total molecular variation (Fig. 3a). Cluster I compressed all species of acids group, while cluster II assembled all mandarin species in a particular group. Additionally, oranges species were placed together as cluster III; meanwhile, grapefruits and pummelos species were place jointly as cluster IV. The outgroup species, kumquat, was separated individually near the zero values of the axis, while the LTR-IRAP data revealed $41.8 \%$ and $60.6 \%$ of the total molecular variation (Fig. 3b).

In comparison with the SSR plot, a clear intersect presented between cluster II (oranges) and cluster III (mandarins) as exposed in guoqing species. However, the LTR-REMAP data revealed $34.2 \%$ and $59.6 \%$ of the total molecular variation (Fig. 4c). Each species was clustered based on their groups except for bitter orange species clustered with the acids group. Overall, the PCoA for SSR data were strongly distinguishable among the genus citrus that is easily detected and clearly divided into four

Table 4 Coefficients correlation $(r)$ among the three markers with similarity matrices for each marker of SSR, LTR-IRAP, and LTR-REMAP markers in 20 citrus genotypes

\begin{tabular}{llll}
\hline & SSR & IRAP & REMAP \\
\hline SSR & 1 & & \\
IRAP & 0.978183 & 1 & 1 \\
REMAP & 0.943912 & 0.950505 & 1 \\
\hline
\end{tabular}

major separate categories by SSR compared to LTRIRAP and LTR-REMAP markers.

Concerning to the genetic structure among the citrus species, we used a non-spatial Bayesian clustering method to determine the best number of subpopulations $(K)$ based on the highest probability and the lowest variance of each possible number of $K$. The obtained citrus population structure was represented in Fig. 4a-c. The SSR markers' output results revealed that, the average estimated in probability score and lowest variance $(\operatorname{LnP}(\mathrm{D}))$, the most probable sub-population number was $K=3$. These results representing that the samples are clustered into three main groups and probably originated from three sub-populations (groups) (Fig. $4 a)$. The first group possesses all number of orange and mandarin species. While the second group compresses all acids species, however, group three collected all species of grapefruit and pummelo. Meanwhile, kumquat partially shared to acids group with small a portion of grapefruit/pummelo and orange/mandarin. On the other hand, sour orange (hybrid) shares genetic diversity with grapefruits/pummelo and orange/mandarin.

Concerning to LTR-IRAP marker (Fig. 4b), the samples are clustered into five sub-populations $(K=5)$. The acid species were clearly distinguished within two clustered, not based on their type but on their sampling origin, while the Egyptian acids are gathered with some portions of the other acids and vice versa. The central group composed mainly of sweet orange species, some of which are partly mixed to the mandarin group, while the last group compresses all species of grapefruit/pummelo with very tiny portions of all other groups (acids, 


\section{a: SSR}

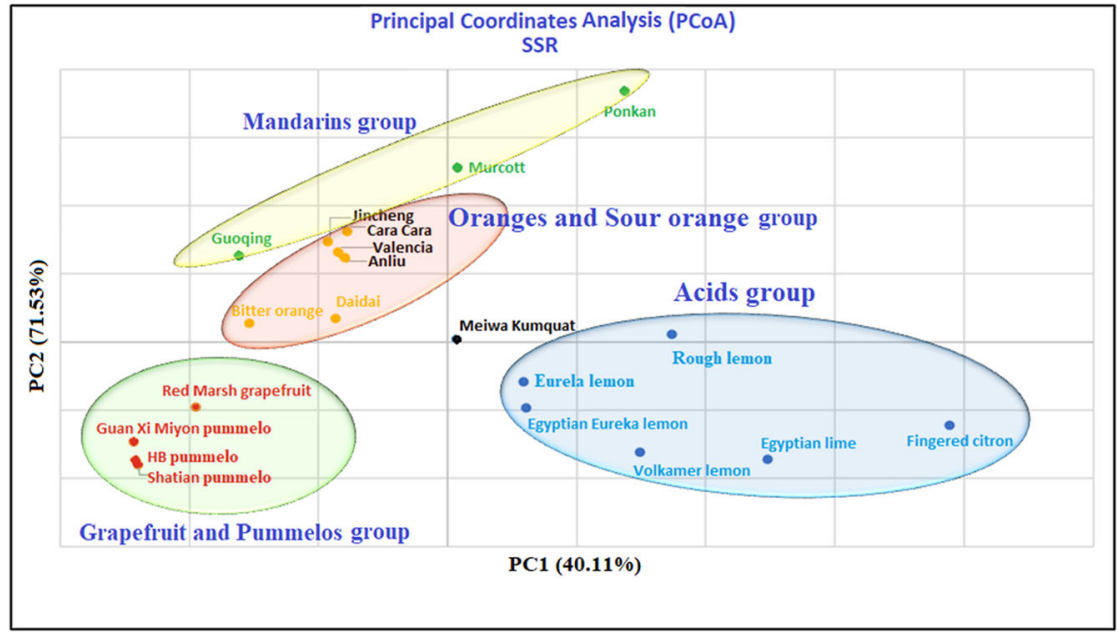

\section{b: LTR-IRAP}

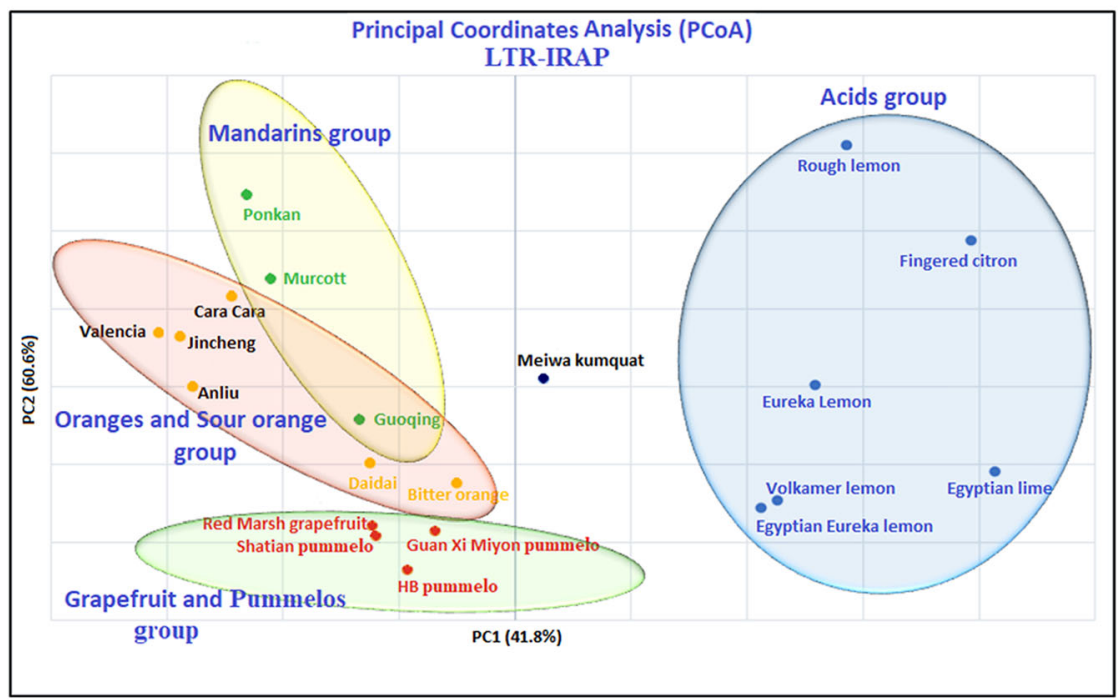

\section{c: LTR- REMAP}

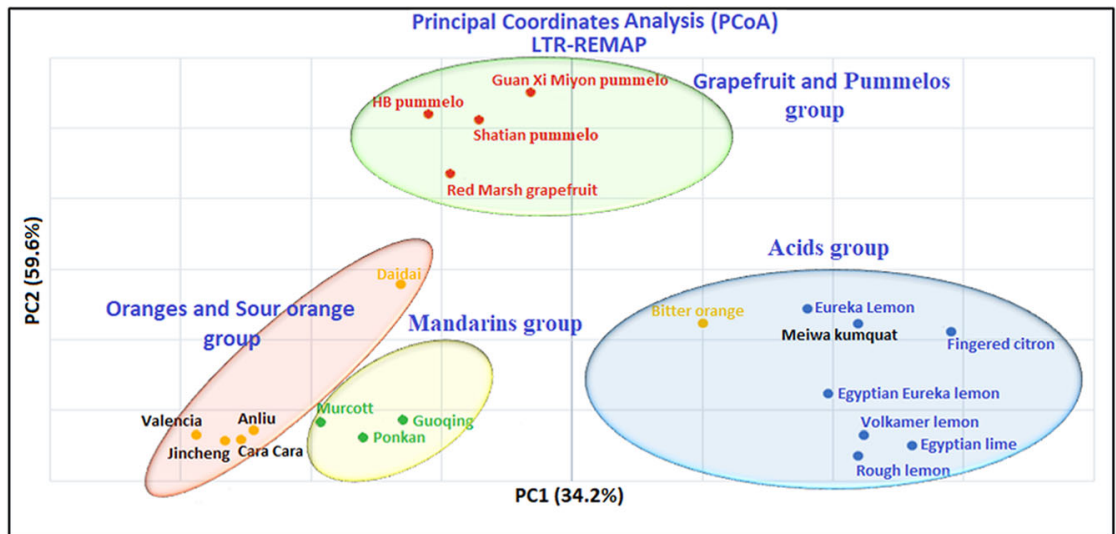

Fig. 3 Schematic representation the principal coordinate analysis (PCOA) among 20 genotypes of citrus and its relatives species via a SSR, $\mathbf{b}$ LTRIRAP, and c LTR-REMAP 


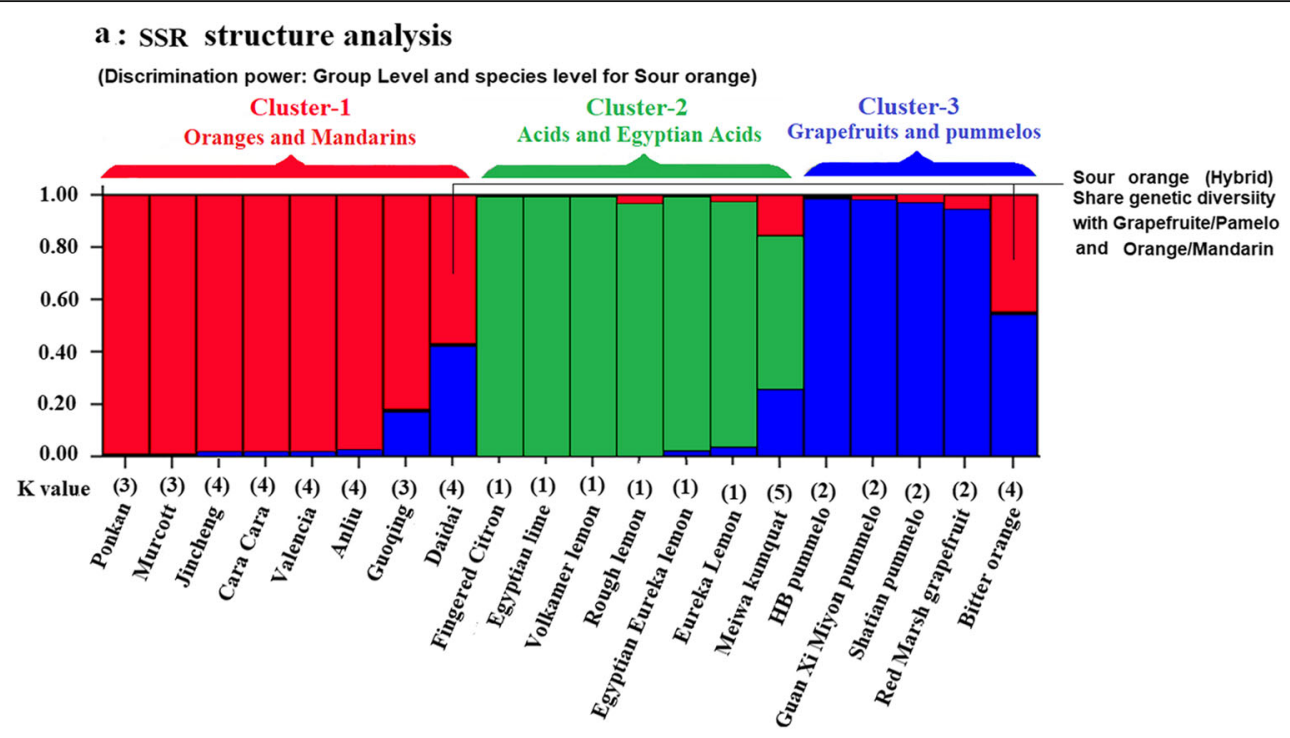

b: LTR-IRAP structure analysis

(Discrimination power: Group Level and species Level for Sour oranges, Navel orange and Origin for Acids)

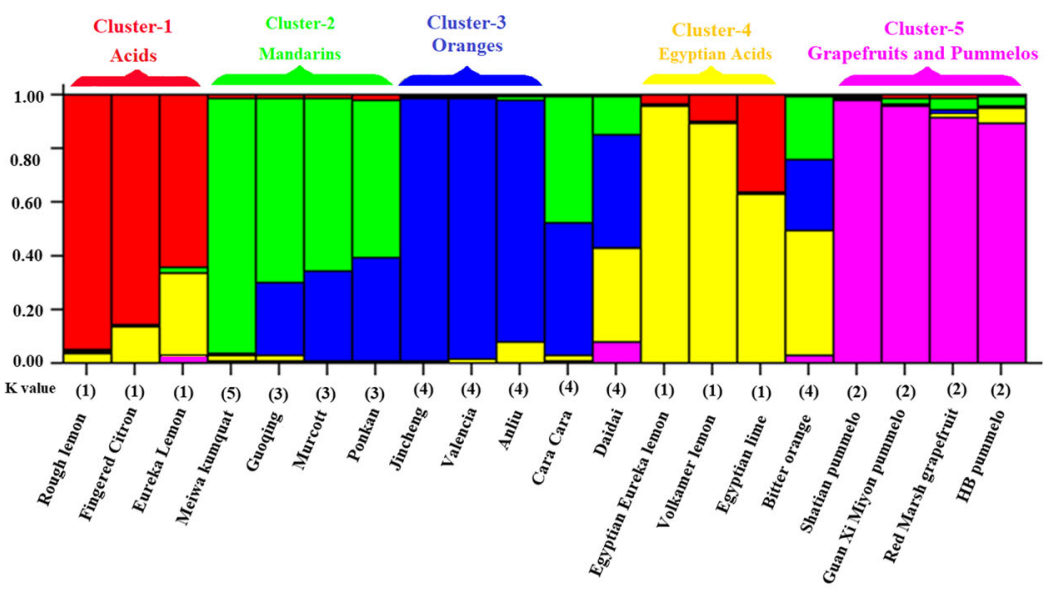

c: LTR- REMAP structure analysis

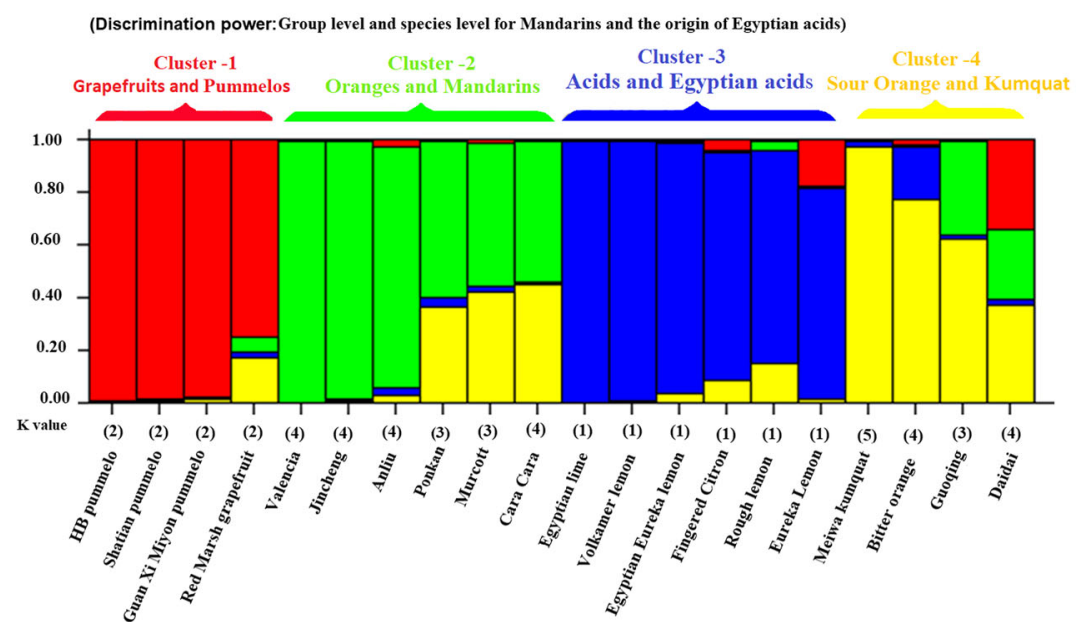

Fig. 4 Structure bar plot graph of 20 genotypes of citrus and its relatives species, a SSR marker $K=3$, $\mathbf{b}$ LTR-IRAP marker $K=5$, and $\mathbf{c}$ LTR-REMAP marker $K=4$. Samples are ordered by group assignment 
mandarin, sweet orange, and Egyptian acids). However, sour orange (Hybrid) share genetic diversity with a small portion of grapefruit/pummelo, while affected with the acids group with equal portions of sweet orange and mandarin, whereas navel orange (hybrid) share genetic diversity with mandarin and sweet orange with a small amount of lemon.

With respect to LTR-REMAP marker (Fig. 4c), the samples are clustered into four sub-populations $(K=4)$. The pummelo species were clearly distinguished within the first clustered while the individual species red marsh grapefruit showed a few mixed portions to kumquat with a weak attachment to orange/mandarin and acids. The second group possesses several attachments, and all sweet orange compress together, while mandarin and navel orange share a high percentage with kumquat, whereas the third group partly shared all species of acids with a small part of grapefruit/pummelo and kumquat. On the other hand, sour orange showed high proportion to kumquat with a mixed portion to acids with a weak attachment to grapefruit/pummelo and orange. However, the hybrid mandarin (guoqing) showed a high percentage of similarity with kumquat while the rest is orange/mandarin with a small acid portion.

\section{Discussion}

Information about the citrus genome and genetic variations present inside and among citrus species and their population's structure can play a useful role in the effective utilization of citrus breeding. Toward this effort, a variety of molecular marker techniques have been utilized during the past few decades. Mining polymorphisms in the DNA sequence of diverse plants are the principal stage toward the progress and application of molecular markers. These polymorphisms can be a gene, part of a gene, a protein, or a sequence in a nongeneration [32]. Presently, several PCR-based systems for marker development exist and have been described in the literature for citrus. However, the progress of molecular DNA markers for genetic analysis has significantly improved our understanding genomes' structure and performance.

In plants, retrotransposons and microsatellites regions have been extremely successful as evident to their abundance. Their ubiquity in the plant kingdom suggests that they are of very ancient origin [33]. Besides, their abundance has played a significant role in genome evolution and structure [34]. The set of SSR, LTR-IRAP, and LTRREMAP markers employed were selected based on previous experiences that allowed us to select those markers that amplify a single locus. In this article, co-dominant marker such as SSR, and the dominant markers LTRIRAP and LTR-REMAP proved to be highly useful tools in discriminating power between the five studied groups of citrus genotypes. Currently, the relatively high values of the effective number of alleles for all the markers used indicate their discrimination power when conducting a large number of specimens. This is very critical for the management of germplasm banks where numerous cultivars need to be identified and correctly [35]. In this revise, SSR provides more effective information on $\mathrm{Na} / \mathrm{b}$, $\% P, \mathrm{Na}, \mathrm{Ne}$, and $I$ compared to LTR-IRAP and LTRREMAP, while the high relatively level in number of private alleles and LComm alleles followed the pattern: LTR-REMAP $>$ LTR-IRAP $>$ SSR. This finding suggested that SSR had discrimination power for group level only and species level for sour orange, while LTR-IRAP is able to discriminate group level, species level, and distinguished the origin of acids. Likewise, LTR-REMAP is qualified for assorting the origin for Egyptian acids and species level for mandarins as well group level, probably due to the principle of the LTR-REMAP marker technique. It is the integration of SSR and LTR-IRAP techniques. Many studies confirmed that a LTR-REMAP marker had the greatest discrimination power and many variations at individual loci within citrus species $[8,9]$. Compared to other regularly used molecular markers such as SSR, the LTR-REMAP markers are better suited for variation in citrus. A feature of LTR-REMAP is that polymorphisms at various loci are discovered in a particular assay, while SSR usually identified polymorphisms at one locus [36]. Recent evidence of the genome sequence suggests that LTR regions occupied about 28.1 $\mathrm{Mb}$, accounting for $9.74 \%$ of the whole genome [20]. This phenomenon is due to the rich presence of $T y-1$ copia retrotransposons owing to a highly diverse polymorphism between the tested of citrus species [37].

Citrus taxonomy and phylogeny are regularly controversial because of the high diversity of phenotypic characters, their long history of cultivation, and complex reproduction system [20]. Our structure analysis results presented shared ancestry between the root-stocked and domesticated citrus species, suggesting that gene flow has occurred between acids, grapefruit and pummelo, mandarin, orange, and kumquat. The outcome of the current structure analysis is, in our opinion, more representative of the populations. However, the genus Fortunella contains the kumquats; it was nested within citrus species, although their morphology is significantly diverse from each other. Several evidence recommended Fortunella was the most simple and primitive genus while citrus was in the top stage of evolution because their fruits are edible and important economically [38]. Within this framework, our results synergistically recommend that Fortunella has interspecific variations, but it is a single independent group as a genus. Indeed, we are able to tentatively imply forward this theory as Fortunella might be less divergent than citrus at the 
molecular level than observed in morphology, concurred with the previously reported by $[8,37,39,40]$.

In this study, the separation of the three true $C$. reticulata, C. medica, and C. maxima in distinct group or subgroup in our LTR-REMAP, SSR, and LTR-IRAP analyses confirms their distinctiveness as the valid basal species of edible citrus. This concept has gained much acceptance and support through previous molecular findings [20, 39, 41, 42].

It is widely believed that sour orange ( $C$. aurantium L.) was the most widespread rootstock in Egypt. Evidence suggested that sour oranges are natural hybrids of mandarin and pummel $[43,44]$. In this study, bitter orange and daidai considered to be sour orange (C. aurantium L.) were nested together with loosely aligned with grapefruit and pummelo. This finding is in agreement with SSR data [45]. Likewise, pummelo is also thought to be a true citrus species [43], which gave rise to sour oranges and grapefruits through hybridization [44]. Indeed, the pummelo genome (C. maxima) has played a part in the parentage of many of the cultivars of citrus [45]. This result confirms that pummelo was the maternal parent of C. sinensis, C. aurantium, C. paradisi, and C. lemon. Our findings agreed with the previously reported of pummelo (C. maxima) (Tanaka classification) [20, 46-48].

The grapefruit (C. paradisi) has notified as a natural hybrid between pummelo (C. maxima) and sweet orange (C. sinensis) [23]. Grapefruit has more significant similarity with pummelo than sweet orange in morphology and chemical constitution, indicating backcross to pummelo. Our data was evolutionarily close grapefruit with pummelo, supporting the viewpoint of a backcross with pummelo. This hypothesis is confirmed by our SSR, LTR-IRAP, and LTR-REMAP data, since the grapefruit accession reveals identity with all pummelo species. Parallel results were obtained by [6, 23, 41, 49-51].

Another striking characteristic, volkamer lemon, appears as one of the excellent control rootstock. Due to their tolerance to biotic and abiotic factors, that is the important purpose for breeding programs. Indeed, it is a more controversial origin [42]. In Egypt, volkamer lemon is the second most promising rootstocks after sour orange (C. aurantium L.). Preliminary data supposed that probably originated from mandarin $\times$ sour orange [44], or lemon $\times$ sour orange [47], or mandarin $\times$ citron origin was also recommended [52]. Recently, it is apparently $C$. medica that was the candidate male parent of $C$. volkameriana, C. aurantifolia, C. jambhiri, and Palestine lime $[42,53]$. In view of the performance of our results, volkamer lemon is classified with all acid citrus (Egyptian lemon and Egyptian lime) as the taxon with which it seems to be highly strongly associated. Herein, our results following the recent theory of nuclear and cytoplasmic data show that citron, lemon, rough lemon, lime, and volkamer lemon were more significant affiliation compare the other citrus and related genera [23, 42, 48].

Several earlier workers hypothesized C. limon to be of complex hybrid origin involving two parents: citron and lime $[16,43,54]$ or citron and sour orange $[47,55]$ or lime and sour orange $[56,57]$. As seen in our results, $C$. limon (Eureka lemon and Egyptian Eureka lemon) reveals that it has a close affinity to C. aurantifolia (Egyptian lime), C. medica (Fingered citron), C. jambhiri (Rough lemon), and C. volkameriana (Volkamer lemon) proves their potential mixture origin, as previously observed by the cytogenetic, phylogenetic, and genomic analysis [20, 52, 58, 59].

The citron mitotype contained only C. medica and is considered a real male parent in citrus breeding. Indeed, using the nuclear and cytoplasmic analysis, [47] revealed that citron was the male parent of Mexican lime, Palestine sweet lime, rangpur lime, volkamer lemon, and rough lemon. This trend was supported by earlier cytoplasmic and nuclear data of Curk et al. [42] who point to $C$. medica as likely to be the directly male parent of lemon and lime; this is due to the shared genomic structure. Our data confirm this hypothesis since the citron mitotype show identity with lime and lemon.

Our data suppose a theory as $C$. reticulata (mandarins) was evolutionarily close with $C$. sinensis (sweet orange), emphasize that $C$. reticulata was shared between mandarins and sweet orange, consistent with the assumptions of Barrett and Rhodes [44] and Nicolosi et al. [47]. Many studies confirmed this opinion as $C$. reticulata and $C$. sinensis were clear signs of the narrow genetic basis and indicated that sweet orange and citron may be female and male parents, respectively $[23,41,60]$. This trend is supported by the recent reclassification of citrus origin [20], confirming that among C. reticulata and C. sinensis, they found a vast assembly of linkage that endorses the domestication of these groups.

\section{Conclusion}

In plant genomes, retrotransposons, and microsatellite elements represent the main abundance component of the structural evolution, differing greatly in copy number within the genome. To facilitate such purposes, here, we report a detailed overview of genetic structure and PCoA analysis based on SSR, LTR-IRAP, and LTR-REMAP approach can capture the genetic relationships and evolution within the genus citrus and related species. Herein, the result of the co-dominant SSR marker can differentiate within the species level of sour orange and has able to be identifying the group level of citrus. However, the dominant LTR-REMAP marker was more sensitive in most discrimination parameter than SSR and LTR-IRAP. It could be classifying the origin of Egyptian acids, species level for mandarins, and the group level of citrus, 
due to it is the integration of SSR and LTR-IRAP techniques. Currently, our finding of the LTR-REMAP structure analysis support the monophyletic nature of the citrus species; able to provide unambiguous identification and disposition of true species and related hybrids like lemon, lime, citron, sour orange, grapefruit, mandarin, sweet orange, pummelo, and fortunella; and resulted in their placement in individual or overlap groups. Interestingly, we observed a thorny of the two Egyptian rootstocks mitotypes, sour orange, and volkamer lemon, supporting the viewpoint that citron was the candidate male parent, while grapefruit/pummelo and mandarin acted acts as the female parent of sour oranges and volkamer lemon. This article offer a useful and potential additional knowledge for breeding programs and conservation approaches as an essential step toward understanding the interspecific admixture and the inferred structure origins of Egyptian citrus rootstock and acid cultivars.

\section{Abbreviations}

SSR: Simple sequence repeats; LTR: Long terminal repeats; RT: Retrotransposons; IRAP: Inter-retrotransposon amplified polymorphism; REMAP: Retrotransposon-microsatellite amplified polymorphism;

PCoA: Principal coordinates analysis

\section{Acknowledgements}

This work is under the activity of the Egyptian Desert Gene Bank, Desert Research Center, Egypt. Special thanks are given to Key Laboratory of Horticultural Plant Biology of MOE, National Center of Citrus Breeding, Huazhong Agricultural University, Wuhan, China, for their valuable support.

\section{Authors' contributions}

MAZ formulated the idea and performed the practical work of genetic diversity experiments, and MA collected the materials, while MAZ, AHM, SN, and MA analyzed the data. MHA wrote the first draft and the final form of the manuscript; meanwhile, SN, MAZ, AHM, and MA review the final form of the manuscript. All authors read and approved the final manuscript.

\section{Funding}

The authors declare no funding for this research.

\section{Availability of data and materials}

The datasets used and/or analyzed during the current study available from the corresponding author on reasonable request.

\section{Ethics approval and consent to participate}

Not applicable.

\section{Consent for publication}

Not applicable.

\section{Competing interests}

The authors declare no competing interests.

Received: 26 October 2020 Accepted: 1 February 2021

Published online: 10 February 2021

\section{References}

1. Xu Q, Chen L, Ruan X, Chen D, Zhu A, Chen C, Bertrand D, Jiao W, Hao B, PLyon M, Chen J, Gao S, Xing F, Lan H, Chang J, Ge X, Le Y, Hu Q, Miao Y, Wang L, Xiao S, Biswas MK, Zeng W, Guo F, Cao H, Yang X, Xu XW, Cheng Y, Xu J, Liu J, Luo OJ, Tang Z, Guo WW, Kuang H, Zhang H, Roose ML, Nagarajan N, Deng XX, Ruan Y (2013) The draft genome of sweet orange (Citrus sinensis). Nat Genet 45:59-66
2. Rohde W (1996) Inverse sequence-tagged repeat (ISTR) analysis, a novel and universal PCR-based technique for genome analysis in the plant and animal kingdom. J Genet Breed 50:249-261

3. Aga E (2005) Molecular genetic diversity study of forest coffee tree [Coffea arabica L.] populations in Ethiopia: implications for conservation and breeding. Doctoral dissertation 1652-6880, 91-576-6978-3.

4. Antonius KK, Kalendar R, Schulman AH (2006) TRIM retrotransposons occur in apple and are polymorphic between varieties but not sports. Theor. Appl. Genet. https://doi.org/10.1007/s00122-005-0203-0

5. Palmieri DA, Novelli VM, Bastianel M, Cristofani-Yaly M, Astúa-Monge G, Carlos EF, Carlos de Oliveira A, Machado MA (2007) Frequency and distribution of microsatellites from ESTs of Citrus. Genet. Mol. Biol. 30:1009-1018

6. Biswas MK, Chai L, Amar MH, Zhang X, Deng XX (2011). Comparative analysis of genetic diversity in Citrus germplasm collection using AFLP, SSAP, SAMPL and SSR markers. Sci Hortic. 129:798-803

7. Choi S, Teakle G, Plaha P, Kim J, Allender C, Beynon E, Piao Z, Soengas P, Han T, King G, Barker G, Hand P, Lydiate D, Batley J, Edwards D, Koo D, Bang J, Park B-S, Lim Y (2007) The reference genetic linkage map for the multinational Brassica rapa genome sequencing project. Theor Appl Genet 115:777-792

8. Biswas MK, Baig MNR, Cheng YJ, Deng XX (2010) Retro-transposon based genetic similarity within the genus Citrus and its relatives. Genet. Resour. Crop Evol. 57(7):963-972

9. Kalendar R (2011) The use of retrotransposon-based molecular markers to analyze genetic diversity. Ratar. Povrt. / Field Veg. Crop Res. 48:261-274

10. Kalendar R, Grob T, Regina M, Suoniemi A, Schulman A (1999) IRAP and REMAP: two new retrotransposon-based DNA fingerprinting techniques. Theor. Appl. Genet. 98:704-711

11. Kalendar R, Schulman AH (2014) Transposon-based tagging: IRAP, REMAP, and iPBS. In Molecular Plant Taxonomy. Humana Press, Totowa, 233-255

12. Kalendar R, Flavell AJ, EllisTHN ST, Moisy C, Schulman AH (2011) Analysis of plant diversity with retrotransposon-based molecular markers. Heredity 106: 520-530

13. Mansour A (2008) Utilization of genomic retrotransposons as cladistic markers. J Cell Mol Biol 7:17-28

14. Grandi FC, An W (2013) Non-LTR retrotransposons and microsatellites: partners in genomic variation. Mobile Genet. Elem 3:e25674

15. Moore GA (2001) Oranges and lemons: clues to the taxonomy of Citrus from molecular markers. Trends Genet. 17:536-540

16. Swingle WT (1943) The botany of Citrus and its wild relatives. In: Webber HJ, Batchelor DL (eds) The citrus industry, Vol 1. University of California, Berkeley, pp 128-474

17. Tanaka T (1977) Fundamental discussion of Citrus classification. Stud. Citrol. 14:1-6

18. Gmitter FG Jr, Chen C, Machado MA, Alves A, Ollitrault P, Froehlicher Y, Shimizu T (2012) Citrus genomics. Tree Genet Genomes 8:611-626

19. Biswas MK, Chai L, Mayer C, Xu Q, Guo WW, Deng XX (2012) Exploiting $B A C$-end sequences for the mining, characterization and utility of new short sequences repeat (SSR) markers in Citrus. Mol. Biol. Rep. 39:53735386

20. Wu GA, Terol J, Ibanez V, López-García A, Pérez-Román E, Borredá C, Domingo C, Tadeo FR, Carbonell-Caballero J, Alonso R, Curk F (2018) Genomics of the origin and evolution of Citrus. Nature 554:311

21. Duran C, Appleby N, Edwards D, Batley J (2009) Molecular genetic markers: discovery, applications, data storage and visualisation. Curr. Bioinformatics 4:16-27

22. Goldschmidt EE (2020) The Citrus genome: past, present and future. In: 1270. The Citrus Genome. Springer, Cham, pp 1-3

23. Uzun A, Yesiloglu T (2012) Genetic diversity in Citrus,(Ed.), 978-953-51-01857, http://www.intechopen.com/books/geneticdiversity-in-plants/geneticdiversity-in-citrus.

24. Cheng YJ, Guo WW, Yi HL, Pang XM, Deng XX (2003) An efficient protocol for genomic DNA extraction from Citrus species. Plant Mol. Biol. Rep. 21:177-177

25. Da Maia LC, Palmieri DA, De Souza VQ, Kopp MM, de Carvalho FIF, Costa de Oliveira A (2008) SSR locator: tool for simple sequence repeat discovery integrated with primer design and PCR simulation. Int J Plant Genom. https://doi.org/10.1155/2008/412696.

26. Amar MH, Biswas MK, Zhang Z, Guo WW (2011) Exploitation of SSR, SRAP and CAPS-SNP markers for genetic diversity of Citrus germplasm collection. Sci Hortic 128:220-227 
27. Xu SB, Tao YF, Yang ZQ, Chu JY (2002) A simple and rapid method used for silver staining and gel preservation. Hereditas 24:335-336

28. Peakall ROD, Smouse PE (2006) GENALEX 6: genetic analysis in Excel. Population genetic software for teaching and research. Molecular ecology notes 6:288-295

29. Schlüter PM, Harris SA (2006) Analysis of multilocus fingerprinting data sets containing missing data. Mol Ecol Notes. 6:569-572

30. Pritchard JK, Stephens M, Donnelly P (2000) Inference of population structure using multilocus genotype data. Genetics 155:945-959

31. Falush D, Stephens M, Pritchard JK (2007) Inference of population structure using multilocus genotype data: dominant markers and null alleles. Mol Ecol Notes 7:574-578

32. Shimizu T, Kacar YA, Cristofani-Yaly M, Curtolo M, Machado MA (2020) Markers, maps, and marker-assisted selection. In: The Citrus genome. Springer, Cham, pp 107-139

33. Bennetzen $J \mathrm{~L}$ (2000) Transposable elements contributions to plant gene and genome evolution. Plant Mol. Biol. 42:347-353

34. Bennetzen $J L$ (2002) Mechanisms and rates of genome expansion and contraction in flowering plants. Genetica. 115:29-36

35. Belaj A, Satovic Z, Cipriani G, Baldoni L, Testolin R, Rallo L, Trujillo I (2003) Comparative study of the discriminating capacity of RAPD, AFLP and SSR markers and of their effectiveness in establishing genetic relationships in olive. Theor. Appl. Genet. 107:736-744

36. Powell W, Morgante M, Andre C, Hanafey M, Vogel J, Tingey S, Rafalski A (1996) The comparison of RFLP, RAPD, AFLP and SSR markers for germplasm analysis. Mol. Breed. 2:225-238

37. Du D, Du X, Mattia MR, Wang Y, Yu Q, Huang M, Yu Y, Grosser JW, Gmitter FG (2018) LTR retrotransposons from the Citrus x clementina genome: characterization and application. Tree Genet. Genomes 14:43

38. Pang XM, Hu DG, Deng XX (2003) Phylogenetic relationships among Citrus and its relatives as revealed by SSR markers. Acta Genet Sin 30:81-87

39. Uzuan A, Yesiloglu T, Aka-Kacar Y, Tuzcu O, Gulsen O (2009) Genetic diversity and relationships within Citrus and related genera based on sequence related amplified polymorphism markers (SRAPs). Sci. Hortic. 121:306-312

40. Omura M, Shimada T (2016) Citrus breeding, genetics, and genomics in Japan. Breed Sci 66(1):3-17

41. Kyndt T, Dung TN, Goetghebeur P, Toan HT, Gheysen G (2010) Analysis of ITS of the rDNA to infer phylogenetic relationships among Vietnamese Citrus accessions. Genet Resour Crop Evol 57:183-192

42. Curk F, Ollitrault F, Garcia-Lor A, Luro F, Navarro L, Ollitrault P (2016) Phylogenetic origin of limes and lemons revealed by cytoplasmic and nuclear markers. Ann. Bot. 117:565-583

43. Scora RW (1975) IX. On the history and origin of Citrus. Bull Torrey Botanical Club 102:369-375

44. Barrett HC, Rhodes AM (1976) A numerical taxonomic study of affinity relationships in cultivated Citrus and its close relatives. Syst Bot 1:105-136

45. Barkley NA, Roose ML, Krueger RR, Federici CT (2006) Assessing genetic diversity and population structure in a Citrus germplasm collection utilizing simple sequence repeat markers (SSRs). Theor Appl Genet 112:1519-1531

46. Green RM, Vardi A, Galun E (1986) The plastome of Citrus Physical map, variation among Citrus cultivars and species, and comparison with related genera. Theoretical and Applied Genetics 72:170-177

47. Nicolosi E, Deng ZN, Genetile A, La Malfa S, Ciontinella G, Tribulata E (2000) Citrus phylogeny and genetic origin of important species as investigated by molecular markers. Theor. Appl. Genet. 100:1155-1166

48. Penjor T, Yamamoto M, Uehara M, Ide M, Matsumoto N, Matsumoto R, Nagano $Y$ (2013) Phylogenetic relationships of Citrus and its relatives based on matK gene sequences. PLoS ONE 8:1-13

49. Fang DQ, Roose ML (1997) Identification of closely related Citrus cultivars with inter-simple sequence repeat markers. Theor Appl Genet 95:408-417

50. Pang XM, Hu CG, Deng XX (2007) Phylogenetic relationships within Citrus and its related genera as inferred from AFLP markers. Genet. Resour. Crop Evol. 54:429-436

51. Mabberley DJ (2008) 21. CITRUS Linnaeus, Sp. PI. 2: 782. 1753. Flora China 11:90-96

52. Carvalho R, Soares Filho WS, Brasileiro-Vidal AC, Guerra M (2005) The relationships among lemons, limes and citron: a chromosomal comparison. Cytogenet. Genome Res. 109:276-282

53. Ollitrault $P$, Jacquemond C, Dubois C, Luro F (2003) Citrus. In: Hamon P, Seguin M, Perrier X, Glassman J (eds) Genetic diversity of cultivated tropical plants. Science Publishers and Cirad, Paris, pp 193-217
54. Malik MN, Scora RW, Soost RK (1974) Studies on the origin of lemon. Hilgardia 42:361-382

55. Gulsen O, Roose ML (2001) Lemons: diversity and relationships with selected Citrus genotypes as measured with nuclear genome markers. J Am Soc Hortic Sci 126:309-317

56. Torres AM, Soost RK, Diedenhofen U (1978) Leaf isosymes as genetic markers in Citrus. Am J Bot 65:869-881

57. Hirai M, Kozaki I (1981) Isozymes of Citrus leaves. Proc Int Soc Citricult 1:1-13

58. Snoussi H, Duval MF, Garcia-Lor A, Belfalah Z, Froelicher Y, Risterucci AM, Perrier X, Jacquemoud-Collet JP, Navarro L, Harrabi M, Ollitrault P (2012) Assessment of the genetic diversity of the Tunisian citrus rootstock germplasm. BMC Genetics. https://doi.org/10.1186/1471-2156-13-16.

59. Amar MH, Hassan AH, Biswas MK, Dulloo E, Xie ZZ, Guo WW (2014) Maximum parsimony based resolution of inter-species phylogenetic relationships in Citrus L.(Rutaceae) using ITS of rDNA. Biotechnol. Biotechnol. Equip. 28:61-67

60. Jena SN, Kumar S, Nair NK (2009) Molecular phylogeny in Indian Citrus L. (Rutaceae) inferred through PCR-RFLP and trnL-trnF sequence data of chloroplast DNA. Sci Hortic 119:403-416

\section{Publisher's Note}

Springer Nature remains neutral with regard to jurisdictional claims in published maps and institutional affiliations.

\section{Submit your manuscript to a SpringerOpen ${ }^{\circ}$ journal and benefit from:}

- Convenient online submission

- Rigorous peer review

- Open access: articles freely available online

- High visibility within the field

- Retaining the copyright to your article

Submit your next manuscript at $>$ springeropen.com 